\title{
Response to reply to the letter to the editor concerning "Gebauer et al.: Subdental synchondrosis and anatomy of the axis in aging: a histomorphometric study on 30 autopsy cases. Eur Spine J 15(3):292-298, 2006": The basis of the dens axis. Where is it located?
}

\author{
Xiao-ping Wang $\cdot$ Zhi-cheng Deng $\cdot$ \\ Zhen-jiao Liang $\cdot$ Yu-min Tu
}

Received: 10 July 2008/ Accepted: 23 September 2008/Published online: 23 October 2008

(C) Springer-Verlag 2008

\section{Dear Editor,}

It was with great interest that we read the timely reply from Dr. Gebauer and Dr. Amling concerning our letter entitled "Letter to the Editor concerning Gebauer et al.: Subdental synchondrosis and anatomy of the axis in aging: a histomorphometric study on 30 autopsy cases. Eur Spine J 15(3):292-298, 2006", which was sent to the Journal's editor.

First, we would like to thank the authors' expound reply. Nevertheless, there exists a lot of unsatisfying arguments in the authors' reply. And we also prepared some evidences to contradict them.

The authors criticized that although our observations of the remnants of the subdental synchondosis on our clinical CT and MRI studies confirm their observations, we draw the wrong conclusion, that the subdental synchondosis located below the level of the $\mathrm{C} 1-\mathrm{C} 2$ articulation must be located at the center of the axis body. Also, the author pointed out that there is no report in the literature describing the subdental synchondosis located at the body of the axis. Unfortunately, we indeed found that there

The reply to this paper is available at doi:10.1007/s00586-008-0809-4.

X. Wang $\cdot$ Z. Deng $\cdot$ Z. Liang $\cdot$ Y. Tu $(\bowtie)$

Department of Orthopaedic Surgery,

Zhongshan Xiaolan People Hospital,

No. 65, JuCheng Road, XiaoLan,

528415 Zhongshan, Guangdong, China

e-mail: yumintu@yahoo.cn

X. Wang

e-mail: xpwang451820@1236.com

Z. Deng

e-mail: zhichengdeng@yahoo.cn

Z. Liang

e-mail: zhenjiaoliang@yahoo.cn existed literature described by Blocky that the remnants of the subdental synchondrosis located at the body of the second vertebrae, "There is a rudimentary island of cartilage in the body of the adult axis. This has been known at least since Bardeen described its origin in 1910" [5]. Fielding et al. also depicted that "At birth, the odontoid process is separated from the body of the axis by a wide cartilaginous plate. This epiphyseal plate does not lie at the anatomical base of the odontoid process (the level of the superior articular facets of the axis), but is situated well below that level-that is, it lies with the body of the axis where it is continuous with the neurocentral synchondrosis." in their article [9].

After carefully reviewing the literatures and our clinical observations on the CT and MRI studies, and even the sagittal and coronal slices of the axis, we are dare to draw this conclusion that the remnants of the subdental synchondosis located below the level of the $\mathrm{C} 1-\mathrm{C} 2$ articulation must be located at the center of the axis body.

Here, we would like to have a review with readers about the axis anatomic features descriptions in the Osteology section of The Bartleby.com edition of Gray's Anatomy of the Human Body, "The most distinctive characteristic of this bone is the strong odontoid process which rises perpendicularly from the upper surface of the body. The body is deeper in front than behind, and prolonged downward anteriorly so as to overlap the upper and fore part of the third vertebra. It presents in front a median longitudinal ridge, separating two lateral depressions for the attachment of the Longus colli muscles. Its under surface is concave from before backward and covex from side to side. The dens or odontoid process exhibits a slight constriction or neck, where it joins the body" [13]. Although there is no distinctive descriptions the exactly border of the axis body, we can at least know that the bony structure below the 
upper surface articulations of $\mathrm{C} 2$ belongs to the axis body. And this is generally accepted by clinical, radiological and morphological experts. Until now most of the literatures concerning the morphological measurements of the dens and the axis body defined as that the dens height was the apex to the level of a plane through the superior-most aspect of the superior articular facets and the height of the C2 vertebral body was determined as from the level of a plane through the superior-most aspect of the superior articular facets to the anterior or the posterior edge of the body along the vertical midline of the second vertebrae $[8$, $14,15,17]$. Also, our observations of the frontal sections of the axis (see Fig. 1a-c) and CT and MRI studies strongly confirm us that the remnants of the subdental synchondosis located at the center of the adult axis body.

We completely agree with the authors' depict on the typical locations for Type II fracture (see authors' Fig. 1a), which is defined as the junction of the odontoid process with the body of the axis according to Anderson and D'Alozo classification [4] - this area is also described as the waist or the neck or the base of the dens by other authors $[6,7,12,14,16]$. Nevertheless, the authors argue that they classified the fracture as Type II (see authors' Fig. 1c, d), because the facture line does not involve the cranial facets of the axis, even though a clear distinction to a Type III fracture is difficult, as the fracture line runs through the transition area between the fracture localizations for Type II and Type III fractures. In the original article of the fracture classification scheme of odontoid fracture introduced by Anderson and D'Alozo, Type II fracture was defined as a fracture occurring at the junction of the odontoid process with the body of the second cervical vertebrae, and in Type III, the fracture line extends downward into the body of the second vertebrae. Obviously, when the fracture line runs through the transition area between the fracture localizations for Type II and
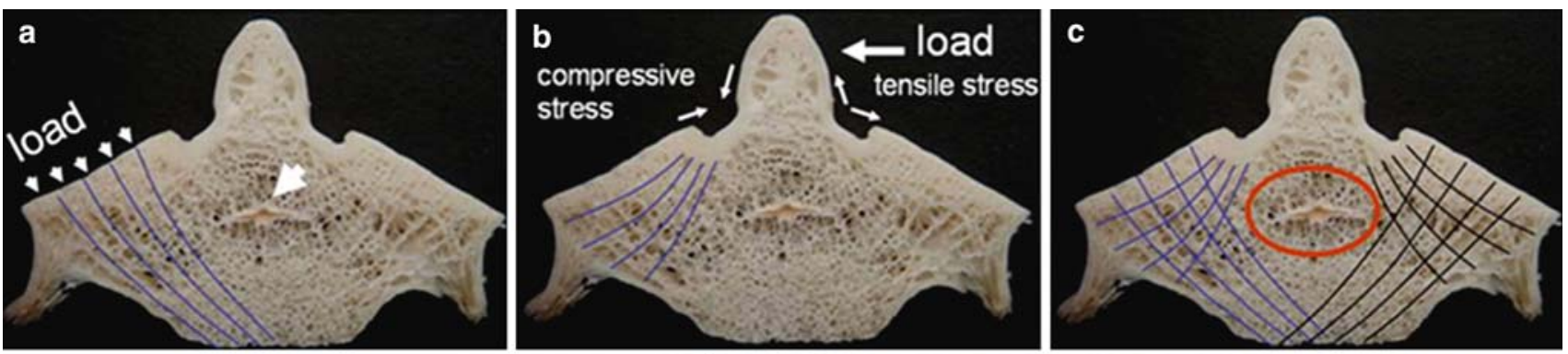

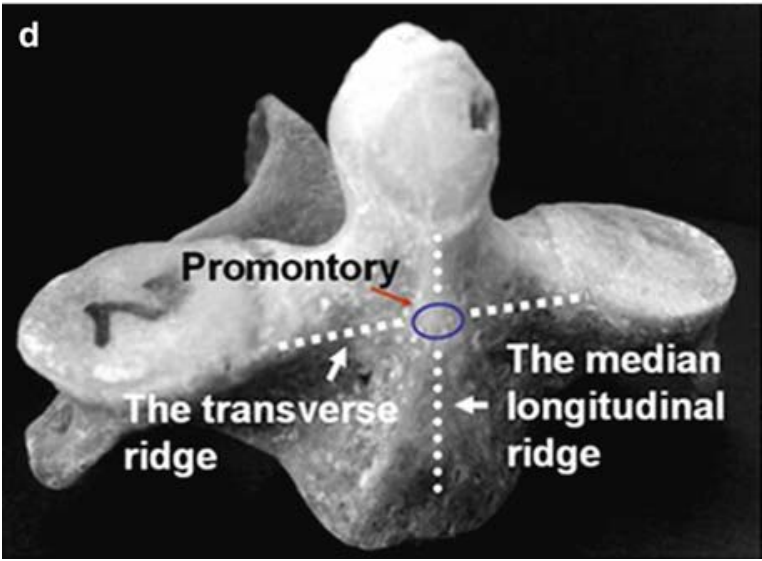

Fig. 1 On the frontal-plane of $\mathrm{C} 2$, two principle trabeculae group are seen to form two arches: one arising from the lateral cortex of the dens to the inferior cortex of the lateral masses of the axis, which is indicating that the load paths from articular facets to the inferior end plate (blue lines, a); and the other taking origin from the superior articulation facets cortex to the $\mathrm{C} 2$ end plate $(\mathbf{b})$, which is indicating that lateral load on the dens, resulting in tensile and compressive stress (blue lines, b). The remnants of the subdental synchondosis locates in the center of the axis body (white arrow a), the decreased intensity trabeculae around the remnants of the subdental synchondosis suggests that this area of bone normally transmits very little load, and it is shielded from a number of forces by the principle



trabeculae group arches of the axis (red circle, $\mathbf{c})$. d The median longitudinal ridge (white longitudinal dashed line) intersects the transverse ridge (white transverse dashed line) forming a "promontory" (blue ellipse) on the anterior surface of the axis. e Bony promontories (white arrows) at the inferior border of the atlantoodontoid joint surface of the odontoid process. White lines represented the articular facets articulation with the anterior arch of atlas. In sagittal-plane of $\mathrm{C} 2$, the remnants of the subdental synchondosis (red arrow) locates in the axis body, decreased intensity trabeculae was observed around the remnants of the subdental synchondosis (blue ellipse) 
Type III fractures, it should be classified as Type III fracture, not Type II fracture, according to Anderson and D'Alozo [4].

In the serial studies of Amling et al. $[1-3,10,11]$ on the internal anatomy of the axis, the authors only studied sagittal slices of the axis. We are sorry to point out that it was of great limitations to reveal the real architecture of the cancellous bone of the axis with only sagittal plane of the axis samples, frontal sections give some additional indications. The trabecular patterns of the axis give significant clues about the normal stresses it bears and transmits. These patterns provide insight into the biomechanical behaviors of $\mathrm{C} 2$. In a frontal section of the axis, two principle trabeculae group are seen to form two arches: one arising from the superior articulation facets cortex to the $\mathrm{C} 2$ end plate (Fig. 1a) and the other taking origin from the lateral cortex of the dens to the inferior cortex of the lateral masses of the axis (Fig. 1b). In particular, we would like to draw the readers' attention that lower intensity trabecular network around the remnants of the subdental synchondosis in the center of the axis body. According to the famous Wolff Law - that the form of bone is produced in response to the stresses that it has to bear. The decreased intensity trabeculae around the remnants of the subdental synchondosis suggests that this area of bone normally transmits very little load. This finding is in accordance with Heggeness and Doherty's finding [14]. It strongly suggests that even obviously decreased mean trabucalar bone volume was observed in this region in sagittal plane of the axis, conclusion that this morphologic characteristic contributes to the occurrence of fractures within this region should not be drawn by the authors. Because the observations were done only in sagittal plane of the axis, and the frontal sections of the axis shows that the decreased intensity trabeculae of this region is most likely a reflection of relatively diminished forces transmitted, and this observation is consistent with the idea that the trabeculae around the remnants of the subdental synchondosis in the axis body is shielded from a number of forces by the principle trabeculae group arches of the axis (see Fig. 1c).

Finally, we would like to describe a new anatomic feature of possible clinical significant observed on the anterior surface body of the $\mathrm{C} 2$, that the axis presents in front a median longitudinal ridge (see Fig. 1d), and also a not obvious transverse ridge (see Fig. 1d) connecting to the lateral masses of the axis. The median longitudinal ridge intersects the transverse ridge forming a "promontory" on the anterior surface of the axis (see Fig. 1d). And the "promontory" is what we use as an important landmark of the axis, that we repeatedly observed the remnants of the subdental synchondosis in adult axis is below this level on CT studies ( $n=43$, age ranging from 10 to 78 years), so we consider it as the inferior boundary of the base of the dens. This anatomic feature may not be clearly observed only on the median sections of the axis, which has been pointed out by the authors. However, as aforementioned, only the sagittal planes studies of the axis could not reveal the real trabecular behaviors of the axis. This "promontory" may not be repeatedly observed on the sagittal planes of the axis samples, but on the complete axis and/or the 3D reconstruction of the axis $\mathrm{CT}$ slices. Again, we are unfortunate to point out that there some errors have been made by the authors in the author's reply, that two black arrows have been marked at the wrong places on sagittal planes of the axis samples (see authors' Fig. 1e, f, the last two axis sagittal sample). Actually, they are the bony promontories at the inferior border of the atlanto-odontoid joint surface of the odontoid process (see Fig. 1e), which can especially be observed in old people, these should not be regarded as "promontory" on the anterior surface of the axis body. Again, it reveals the limitations of only study on the sagittal plane of the axis samples by the authors.

Again we thank the authors for this fruitful discussion, and we are extremely happy to participate in this elaborate discussion on this issue, and also we are expecting more experts participate in this discussion.

Acknowledgments The authors would like to express their grateful thanks to William Orr MD and John K. Lim MD, FACS for their assistance in revising of the manuscript.

\section{References}

1. Amling M, Hahn M, Wening VJ et al (1994) The microarchitecture of the axis as the predisposing factor for fracture of the base of the odontoid process. A histomorphometric analysis of twenty-two autopsy specimens. J Bone Joint Surg Am 76(12):1840-1846

2. Amling M, Posl M, Wening VJ et al (1995) Structural heterogeneity within the axis: the main cause in the etiology of dens fractures. A histomorphometric analysis of 37 normal and osteoporotic autopsy cases. J Neurosurg 83(2):330-335

3. Amling M, Posl M, Ritzel H et al (1996) Architecture and distribution of cancellous bone yield vertebral fracture clues. A histomorphometric analysis of the complete spinal column from 40 autopsy specimens. Arch Orthop Trauma Surg 115(5):262269. doi:10.1007/BF00439050

4. Anderson LD, D'Alonzo RT (1974) Fractures of the odontoid process of the axis. J Bone Joint Surg Am 56(8):1663-1674

5. Blockey NJ, Purser DW (1956) Fractures of the odontoid process of the axis. J Bone Joint Surg Br 38-B(4):794-817

6. Brant-Zawadzki M, Miller EM, Federle MP (1981) CT in the evaluation of spine trauma. AJR Am J Roentgenol 136(2):369-375

7. Bohlman HH (1997) Acute fractures and dislocations of the cervical spine. An analysis of three hundred hospitalized patients and review of the literature. J Bone Joint Surg Am 61(8):1119-1142

8. Doherty BJ, Heggeness MH (1995) Quantitative anatomy of the second cervical vertebra. Spine 20(5):513-517. doi:10.1097/ 00007632-199503010-00002

9. Fielding JW, Hensinger RN, Hawkins RJ (1980) Os Odontoideum. J Bone Joint Surg Am 62(3):376-383 
10. Gebauer M, Barvencik F, Beil FT et al (2007) Subdental synchondrosis. Computed tomographic and histologic investigation on morphological aspects of fracture at the base of the dens in 36 human axis specimens. Unfallchirurg 110(2):97-103. doi: 10.1007/s00113-006-1201-7

11. Gebauer M, Lohse C, Barvencik F et al (2006) Subdental synchondrosis and anatomy of the axis in aging: a histomorphometric study on 30 autopsy cases. Eur Spine 15(3):292-298. doi: 10.1007/s00586-005-0990-7

12. Gehweiler JA Jr, Martinez S, Clark WM et al (1977) Spondylolisthesis of the axis vertebra. AJR Am J Roentgenol 128(4):682684

13. Gray H (1918) The cervical vertebrae osteology. Gray's anatomy of the human body. The Bartleby.com edition. http://www. bartleby.com/107/
14. Heggeness MH, Doherty BJ (1993) The trabecular anatomy of the axis. Spine 18(14):1945-1949

15. Heller JG, Alson MD, Schaffler MB et al (1992) Quantitative internal dens morphology. Spine 17(8):861-866. doi:10.1097/ 00007632-199208000-00001

16. Henry AD, Bohly J, Grosse A (1999) Fixation of odontoid fractures by an anterior screw. J Bone Joint Surg Br 81(3):472477. doi:10.1302/0301-620X.81B3.9109

17. Schaffler MB, Alson MD, Heller JG et al (1992) Morphology of the dens. A quantitative study. Spine 17(7):738-743. doi: 10.1097/00007632-199207000-00002 